has emphasized those studies which he thinks have given the most useful insight into retinal function. This sometimes leads to a rather unusual weight being given to different topics. Thus, on phototransduction, the visual pigment and its reactions following light absorption are described in detail over five pages, while the subsequent chain of reactions involving cyclic GMP (whose recent unravelling has been a major success in retinal research) are described cursorily in less than two; the recently disproved calcium hypothesis of phototransduction is not mentioned. Similarly, Enroth-Cugell and Robson's important experiment distinguishing $\mathrm{X}$ and $\mathrm{Y}$ ganglion cells is only thought to be worth describing in a footnote, while ten pages are devoted to Dowling's studies of the effects of dopamine on horizontal cells. Quantitative analyses of retinal function, such as Lamb and Simon's work on the electrical coupling of retinal cells, are largely neglected.

Finally, the descriptions in this book of what occurs in the retina could have been accompanied by more analysis of why it occurs. Readers who want to know why the retina segregates visual information into $\mathrm{ON}$ and $\mathrm{OFF}$ channels, why there are sustained and transient ganglion cells, or why bipolar and ganglion cells have receptive fields with an excitatory centre and an inhibitory surround, will not find such issues discussed in any detail here, despite their relevance, for example, to Marr's theories of early visual processing.

This is a useful book. But it would have better served the graduate student entering the field if it had followed the philosophy of its subtitle, and given a broader view of retinal function.

David Attwell is in the Department of Physiology, University College London, Gower Street, London WC1E $6 B T$, UK.

\section{Reactions to risk}

\section{John Dunster}

The Politics of Anxiety: Sellafield's Cancer-Link Controversy. By S.M. Macgill. Pion, 207 Brondesbury Park, London NW2 5JN: 1987. Pp.198. Pbk£14.95.

Most of those involved in risk estimation and its practical application now recognize that the estimate of a risk and the fear of a risk are not closely related. The fear, or 'perception' in the jargon of the trade, is no longer seen as irrational or the result of ignorance; it is recognized as real, perhaps more real than the risk creating it. We appreciate the need to assess these fears and to understand how they arise. Creating them and exacerbating them is easy enough. We would like to know how to assuage them when they seem to be excessive. Even more, we would like to know how best to incorporate them into the process of managing and regulating risks. This book helps with the understanding but offers little help in its application.

On the whole, the book is carefully and clearly written, with few lapses into jargon, but the reader's patience may be strained throughout Chapter 1 by an excessive use of parentheses. The later chapters are mercifully less encumbered.

To me, the most fascinating parts of the book are those summarizing the reactions of the West Cumbrian public to the presence of the nuclear plant at Sellafield, to the Yorkshire Television documentary, The Nuclear Laundry, and to the Black Report of 1984 which was the result of an inquiry into the incidence of leukaemia around Sellafield. This type of information is extremely difficult to summarize and it says much for the author's clarity of thought and presentation that these chapters are compelling reading. They seem to me, a layman in this area, to be examples of social science at its best.

The later chapters on risk assessment and on the logic and science of the Black Report impressed me less. It may be that the author has chosen to restrict her source material to the Black Report, but I suspect that a basic lack of expertise is more to blame. There is really no excuse for failing to recognize that the radiobiological approach offered to Black led to a forecast 400 times smaller than the observed excess rather than 40 times. The latter figure comes from a somewhat implausible modification made in the Black Report attributing all childhood leukaemia everywhere to radiation. The point is brought out clearly in Para 4.50 of the Report. There is some evidence of bias in this part of the book, probably stemming from an excessive dependence on the reports of Black and COMARE (Committee on the Medical Aspects of Radiation in the Environment).

Here, too, there are some weaknesses of logic. The author is puzzled that Black should think that a larger factor between the calculated and the observed number of leukaemias would decrease the likelihood that the releases from Sellafield have caused the leukaemias. She believes that a larger factor would strengthen the $a$ priori case against Sellafield. She fails to distinguish between the existence of the works at Sellafield and the possible causal mechanism. She also appears to think that an excess that is statistically significant must necessarily have a cause. In fact, the excess at Seascale is unlikely to be due to blind chance, but the possibility cannot be excluded until a convincing explanation can be found. Either the author deals with physical and biological science less well

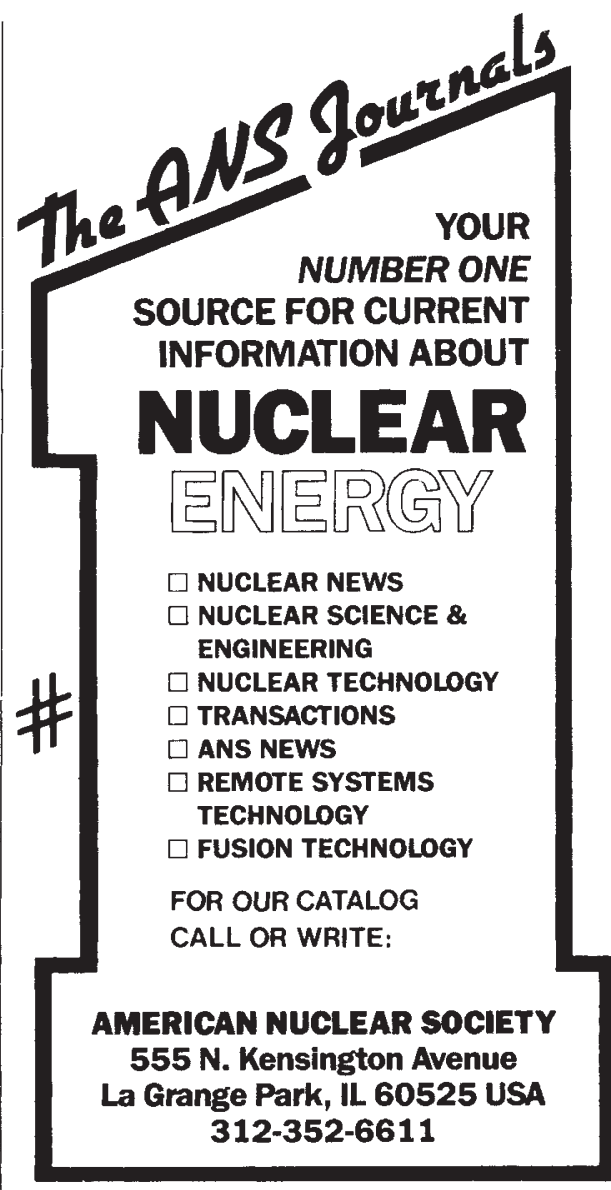

Reader Service No.16

than with social science, or I am a harsher judge in the areas I know best.

The final chapter, "Summary and Outlook", is disappointing. The author sees her aim as "to reemphasise and so to bring more fully to the fore a number of underacknowledged, ignored, or newly emerging factors, with the intention of encouraging greater awareness of the true character of the context for future public policy for dealing with risk controversies". None of the factors dealt with in the book justify those adjectives, although it was worth re-stating them lest they be forgotten. But that is not the issue that makes this book worthwhile. Its value lies in showing that preconceived notions of what people think are suspect, and that the sources of information available to the general public are inadequate. It is not necessarily true that better and more complete information will lead to less unjustified fear and to less complacency, but without better information in better forms there is no way forward. Descriptive sociology, like descriptive biology, may be of limited use and is easy to criticize, but it is a vital starting point. This book is necessary reading. It is not, and could not be, sufficient.

John Dunster, 52 Thames Street, St Ebbes, Oxford $O X I$ ISU, UK, recently retired as Director of the National Radiological Protection Board. 